\title{
CONSORT Statement for Randomized Trials of Nonpharmacologic Treatments: A 2017 Update and a CONSORT Extension for Nonpharmacologic Trial Abstracts
}

\author{
Isabelle Boutron, MD, PhD; Douglas G. Altman, DSc; David Moher, PhD; Kenneth F. Schulz, PhD, MBA; and \\ Philippe Ravaud, MD, PhD, for the CONSORT NPT Group*
}

\begin{abstract}
Incomplete and inadequate reporting is an avoidable waste that reduces the usefulness of research. The CONSORT (Consolidated Standards of Reporting Trials) Statement is an evidencebased reporting guideline that aims to improve research transparency and reduce waste. In 2008, the CONSORT Group developed an extension to the original statement that addressed methodological issues specific to trials of nonpharmacologic treatments (NPTs), such as surgery, rehabilitation, or psychotherapy. This article describes an update of that extension and presents an extension for reporting abstracts of NPT trials. To develop these materials, the authors reviewed pertinent literature published up to July 2016; surveyed authors of NPT trials; and conducted a consensus meeting with editors, trialists, and methodologists.

Changes to the CONSORT Statement extension for NPT trials include wording modifications to improve readers' understanding and the addition of 3 new items. These items address whether and how adherence of participants to interventions is
\end{abstract}

assessed or enhanced, description of attempts to limit bias if blinding is not possible, and specification of the delay between randomization and initiation of the intervention. The CONSORT extension for abstracts of NPT trials includes 2 new items that were not specified in the original CONSORT Statement for abstracts. The first addresses reporting of eligibility criteria for centers where the intervention is performed and for care providers. The second addresses reporting of important changes to the intervention versus what was planned. Both the updated CONSORT extension for NPT trials and the CONSORT extension for NPT trial abstracts should help authors, editors, and peer reviewers improve the transparency of NPT trial reports.

Ann Intern Med. 2017;167:40-47. doi:10.7326/M17-0046

Annals.org For author affiliations, see end of text.

This article was published at Annals.org on 20 June 2017.

* For a list of members of the CONSORT NPT Group, see Appendix 1 (available at Annals.org)

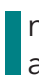
ncomplete reporting is responsible for a great deal of avoidable waste in research $(1,2)$. The CONSORT (Consolidated Standards of Reporting Trials) Statement (3-5), an evidence-based reporting guideline, was developed to improve research transparency.

Nonpharmacologic treatments (NPTs), such as surgery, rehabilitation, education, psychotherapy, and devices, represent a wide range of interventions. However, assessing NPTs raises specific methodological issues related to the complexity of the intervention, the influence of care providers, the expertise of the center, and the difficulties of blinding (6-14). To account for these issues, the CONSORT Group developed a CONSORT Statement extension for trials of NPTs ("CONSORT NPT extension"), which was published in Annals of Internal Medicine in $2008(15,16)$.

In 2010, the main CONSORT Statement was updated $(5,17)$. To account for this update and methodological developments since publication of the original NPT extension, we aimed to update the CONSORT NPT extension and develop a CONSORT extension for reporting abstracts of NPT trials $(18,19)$.

\section{MeTHODS}

We updated the CONSORT NPT extension in 3 steps. First, we reviewed the literature to identify up-todate evidence. The search is detailed in Appendix 2 (available at Annals.org). Second, we surveyed corresponding authors of published articles citing the 2008 CONSORT NPT extension. Of the 1525 authors invited by e-mail, 194 (13\%) participated. For each item of the CONSORT NPT extension, participants were asked to indicate whether they believed the item should be modified and, if so, why and how. The results of the survey are reported in Appendix Tables 1 and 2 (available at Annals.org). From the literature review and the survey, we synthesized proposals for changes to each item. Finally, we organized a 2-day consensus meeting in May 2014 in Paris, France, with 22 participants (9 editors, 6 trialists, and 7 methodologists). During this meeting, the survey results and proposals for change were presented and each item was discussed until consensus was reached. After the meeting, we developed a draft of the current manuscript, which was sent to all participants for comments. The updated checklist was not modified at this stage.

\section{Updating the CONSORT NPT Extension Main Changes to the CONSORT NPT Extension}

The revision of the CONSORT NPT extension checklist consisted of the deletion of items, the addition of new items, wording changes, and reformatting. The numbering and content of items were adjusted to follow the 2010 CONSORT Statement. Some wording was changed to improve readers' understanding, such as the use of "care providers" instead of "those performing the intervention" in item 3 .

Items $11 \mathrm{a}$ and $11 \mathrm{~b}$, related to blinding, were modified because they were incorporated into the 2010 CONSORT Statement. Three new items were added to account for the difficulties in replicating NPTs, the frequent lack of blinding, and the risk for a differential 


Table 1. 2017 CONSORT Checklist of Information to Include When Reporting Randomized Trials Assessing NPTs*
$\begin{aligned} & \text { Checklist Item Number, by } \\ & \text { Section/Topic Item }\end{aligned}$

\section{Title and abstract}

$1 \mathrm{a}$

$1 \mathrm{~b}$

\section{Introduction \\ Background and objectives \\ $2 a$ \\ $2 b$}

Methods

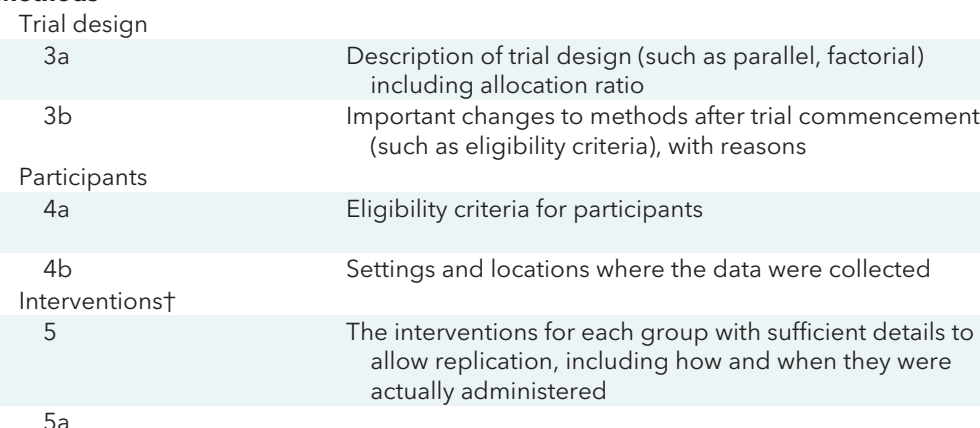

$5 a$

\section{$5 b$}

$5 c$

$5 d$

Outcomes

$6 a$

$6 b$

Sample size

$7 a$

$7 b$

Randomization

Sequence generation

$8 a$

$8 b$

Allocation concealment mechanism

9

10

Blinding

$11 a$

$11 b$

$11 \mathrm{c}$

Identification as a randomized trial in the title conclusions (for specific guidance see CONSORT for abstracts)

Scientific background and explanation of rationale Specific objectives or hypotheses

escription of trial design (such as parallel, factorial)

portant changes to methods after trial commencement

Completely defined pre-specified primary and secondary outcome measures, including how and when they were assessed

Any changes to trial outcomes after the trial commenced, with reasons

How sample size was determined

When applicable, explanation of any interim analyses and stopping guidelines

Method used to generate the random allocation sequence

Type of randomization; details of any restriction (such as blocking and block size)

Mechanism used to implement the random allocation sequence (such as sequentially numbered containers), describing any steps taken to conceal the sequence until interventions were assigned

Who generated the random allocation sequence, who enrolled participants, and who assigned participants to interventions

If done, who was blinded after assignment to interventions (for example, participants, care providers, those assessing outcomes) and how

If relevant, description of the similarity of interventions
Structured summary of trial design, methods, results, and Refer to CONSORT extension for abstracts for NPT trials

When applicable, how care providers were allocated to each trial group

When applicable, eligibility criteria for centers and for care providers

Precise details of both the experimental treatment and comparator

Description of the different components of the interventions and when applicable, description of the procedure for tailoring the interventions to individual participants.

Details of whether and how the interventions were standardized.

Details of whether and how adherence of care providers to the protocol was assessed or enhanced

Details of whether and how adherence of participants to interventions was assessed or enhanced
When applicable, details of whether and how the clustering by care providers or centers was addressed
If done, who was blinded after assignment to interventions (e.g., participants, care providers, those administering co-interventions, those assessing outcomes) and how

If blinding was not possible, description of any attempts to limit bias

Continued on following page 


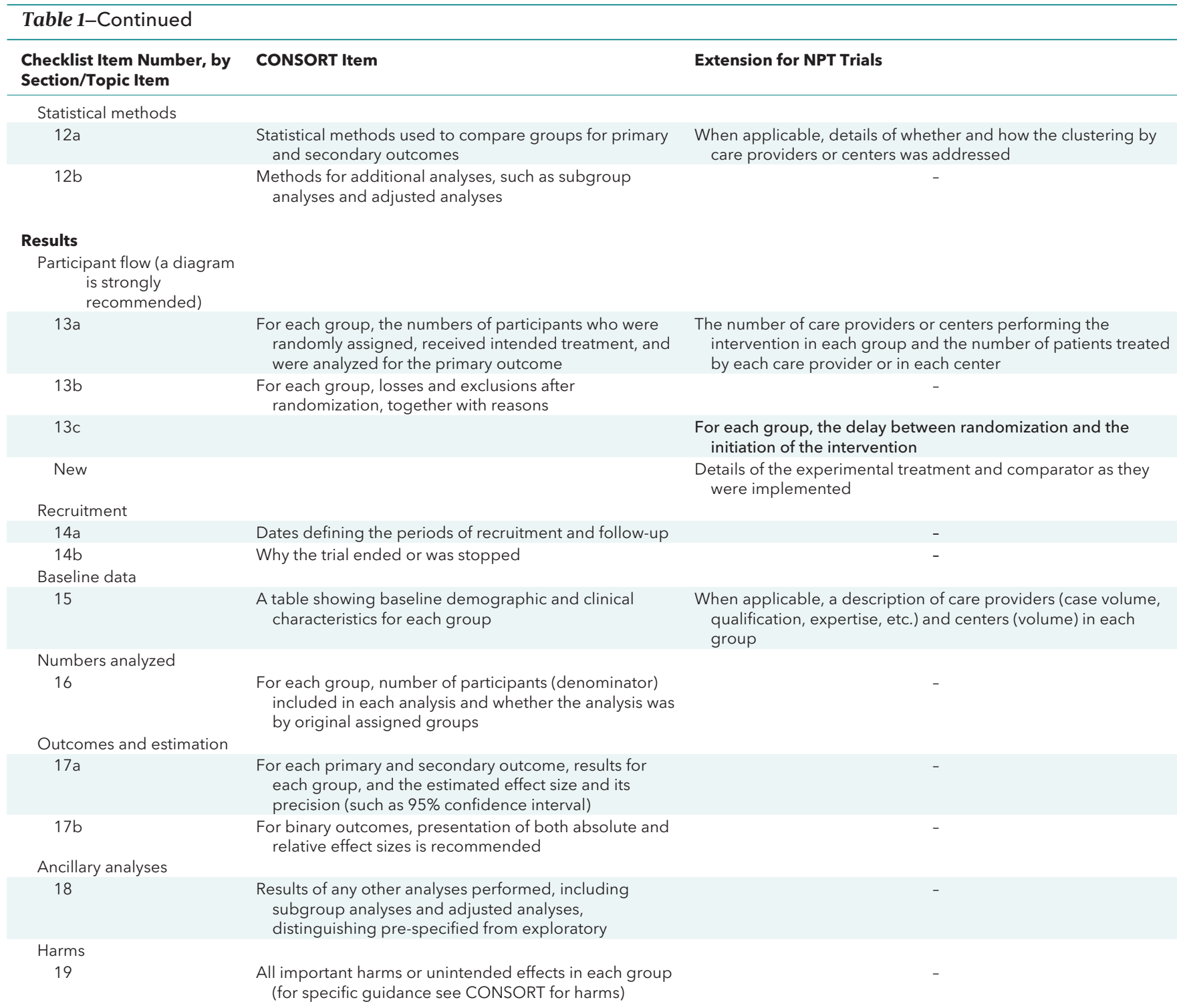

\section{Discussion}

Limitations

20

Generalizability 21

\section{Interpretation}

22

\section{Other information}

Registration

23

Protocol

24

Funding

25
Trial limitations, addressing sources of potential bias, imprecision, and, if relevant, multiplicity of analyses

Generalizability (external validity, applicability) of the trial findings

Interpretation consistent with results, balancing benefits and harms, and considering other relevant evidence
In addition, take into account the choice of the comparator, lack of or partial blinding, and unequal expertise of care providers or centers in each group

Generalizability (external validity) of the trial findings according to the intervention, comparators, patients, and care providers and centers involved in the trial

CONSORT $=$ Consolidated Standards of Reporting Trials; NPT = nonpharmacologic treatment

* Additions or modifications to the 2010 CONSORT checklist. Modifications of the extension are in boldface.

† These items are consistent with the Template for Intervention Description and Replication (TIDieR) checklist. 
delay between randomization and initiation of the intervention. These items are dedicated to whether and how adherence of participants to interventions is assessed or enhanced (item $5 \mathrm{~d}$ ), the description of any attempts to limit bias if blinding is not possible (item 11c), and the delay between randomization and initiation of the intervention (item 13c).

The updated NPT checklist is shown in Table 1, with examples of adequate reporting in Appendix Table 3 and Appendix Figures 1 and 2 (available at Annals.org). The modified participant flow diagram is presented in the Figure.

\section{Development of the CONSORT Extension for Reporting Abstracts of NPT Trials}

The CONSORT extension for abstracts was published in 2008 (18). We added 2 new items to this extension: one for reporting "eligibility criteria for centers where the intervention is performed and for care providers", and one for "any important changes to the intervention delivered from what was planned" (Table 2). Appendix Table 4 (available at Annals.org) provides examples of published abstracts that we modified to adhere to the CONSORT extension for abstracts of NPT trials.

\section{Specific Methodological Issues Considered in the Update to the CONSORT NPT Extension}

Complexity of NPTs. Nonpharmacologic treatments frequently involve multicomponent interventions delivered by multiple care providers, and each component or provider may influence the success of the overall intervention (20). Nonpharmacologic treatments are difficult to describe and standardize, and the "active ingredients" are sometimes difficult to disentangle (21). Furthermore, the intervention that is actually administered may differ substantially from the one that was planned.

To account for these issues, the updated CONSORT NPT extension recommends providing a description of the components of the intervention and, when applicable, a description of the procedure for tailoring the intervention to individual participants (item $5 a$ ) in the methods section. We also recommend describing whether and how the interventions were standardized (item 5b), whether and how adherence of care providers to the protocol was assessed or enhanced (item 5c), and whether and how adherence of participants to interventions was assessed or enhanced (item $5 d$ ).

In the results section, authors should report details of the experimental treatment and comparator as they were implemented (new item). In the abstract, authors should report "any important changes to the intervention delivered from what was planned".

These items are consistent with the Template for Intervention Description and Replication (TIDieR) checklist and guidance (22).

Influence of Center and Care Provider Expertise.

For most NPT trials, the volume of the center providing the intervention and the expertise of the care pro- viders can greatly affect estimates of treatment effect. Interventions that are beneficial in one setting may be less effective or even harmful in another setting (23). Furthermore, in NPT trials comparing interventions that could be performed by the same care provider (for example, surgical procedures), different methods for allocating care providers to each group are possible-care providers can deliver the intervention in both groups or only 1 group. All of these choices can raise specific methodological and logistical issues (Appendix Table 5, available at Annals.org).

The updated CONSORT NPT extension recommends reporting how care providers were allocated to each trial group (item 3a), eligibility criteria for centers and care providers (item $4 a$ ), the number of care providers or centers performing each intervention and the number of patients treated by each care provider or in each center (item 13a), and a description of care providers (for example, case volume, qualification, and expertise) and centers (volume) in each group (item 15).

Furthermore, the flow diagram (item 13a) includes a supplementary box to report the number of care providers or centers performing the intervention in each treatment group and the number of patients treated by each care provider or in each center (Figure). The flow diagram should report summary statistics, but the detailed description of the number of patients included and treated in each center and each group could be reported in an appendix. This information is particularly important because the interpretation and applicability of the results vary considerably if, for example, 1 highvolume surgeon in 1 high-volume center performs $90 \%$ of the interventions or if the interventions are welldistributed in all centers and among all surgeons. Finally, authors should discuss the limitations related to any differing expertise of care providers or centers in each group (item 20) and the generalizability according to the care providers and centers involved in the trial (item 21). In the abstract, we also recommend reporting eligibility criteria for care providers and centers where the intervention is performed.

Clustering. In individual randomized controlled trials (RCTs), standard sample size calculations and statistical analyses assume that the outcome for each participant is independent. However, this may not be true in individual NPT RCTs in which the outcomes tend to be more similar for patients treated by the same care provider than by other care providers (24). Lack of accounting for this type of clustering by care providers and centers may lead to an underestimation of the sample size required and result in imprecision (25-27). Many analysis methods, such as fixed-, random-, or mixed-effects models and generalized estimating equations, are available to account for clustering $(28-30)$.

The updated CONSORT NPT extension recommends reporting details of whether and how the clustering by care providers or centers was addressed in the sample size calculation (item 7a) and the statistical analysis (item 12a).

Difficulties of Blinding. Blinding of patients and care providers is frequently impossible in trials assessing NPTs and often relies on complex methods when it 
Figure. Modified CONSORT flow diagram for individual randomized controlled trials of nonpharmacologic treatments.

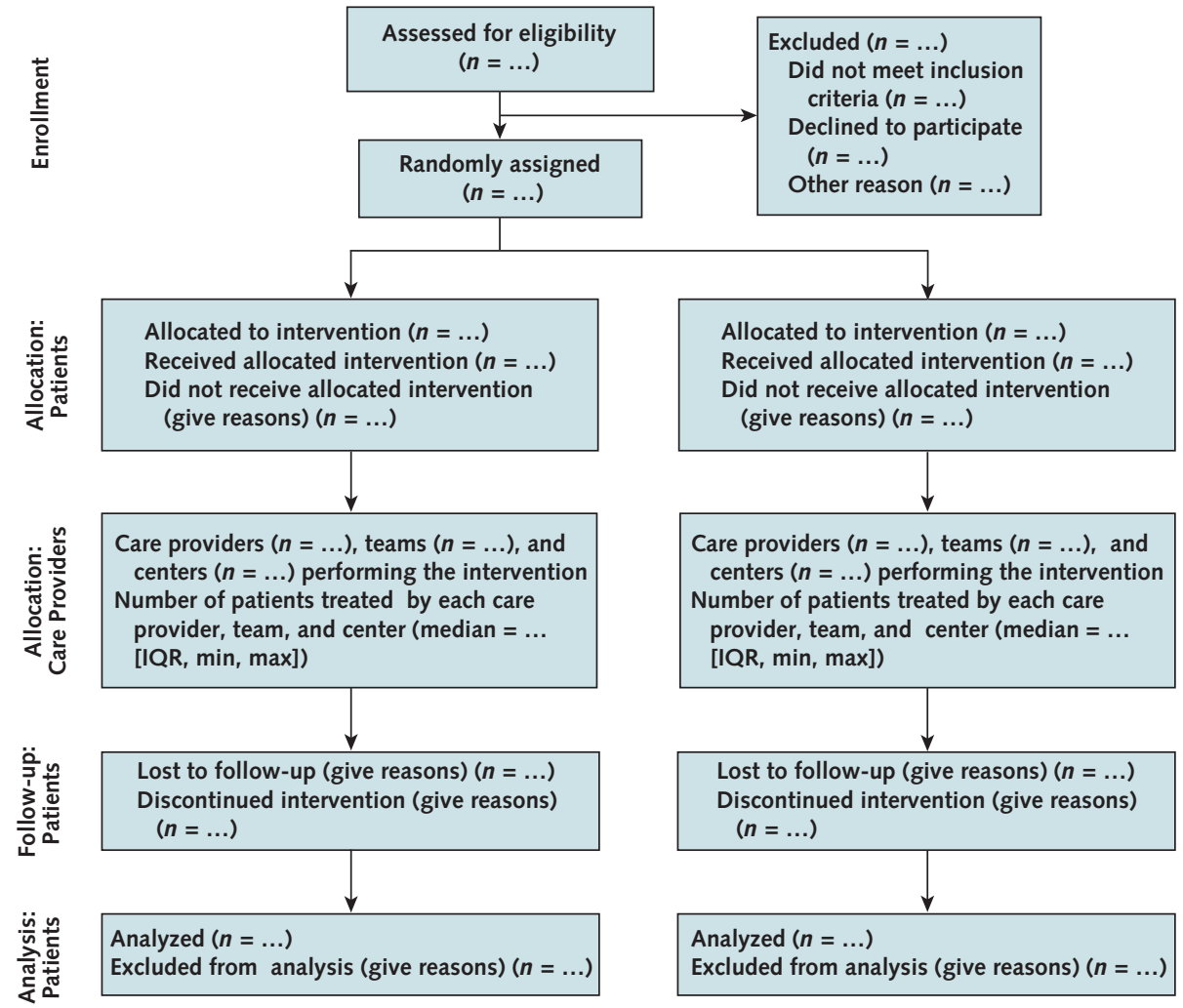

An extra box relating to care providers and centers has been added for each intervention group. CONSORT = Consolidated Standards of Reporting Trials; $I Q R=$ interquartile range; $\max =$ maximum; $\min =$ minimum.

is possible $(9,31)$. Some of these methods rely on blinding other care providers who do not perform the intervention but who will care for the patients after the intervention. To account for this, item 11a was modified slightly.

If blinding is not possible in a trial, the updated CONSORT NPT extension recommends reporting this information explicitly and providing a description of any attempts to limit bias, such as collection of data by an independent researcher (item 11c). Furthermore, the authors are advised to discuss the limitations related to the lack of blinding when relevant (item 20).

Delay Between Randomization and Initiation of the Intervention. For most NPT RCTs, a delay may occur between randomization and delivery of the intervention (32). This delay is typically related to logistical issues owing, for example, to scheduling hospitalizations or visits with the care provider (33). Such a delay could lead to crossover, loss to follow-up, or nonadherence to the intervention if the participant's status changes between randomization and intervention. The delays can be unequal between trial groups; for example, a trial comparing chemonucleolysis and manipulation in patients with lumbar disc herniation had an average delay of 3 weeks in one group and 13 weeks in the other group (34). The updated CONSORT NPT extension recommends reporting "for each group, the delay between randomization and initiation of the intervention" (item 13c) in the results section.

\section{Adherence to the Original CONSORT NPT Extension}

Several systematic reviews showed poor adherence to the original CONSORT NPT extension. Only $39 \%$ of NPT interventions were adequately described in NPT trial reports (35). A systematic evaluation of surgical RCTs showed that only $6 \%$ and $4 \%$ reported how clustering was addressed in the sample size calculation and statistical analysis, respectively (36).

\section{Discussion}

The updated CONSORT NPT extension should enable authors to increase the transparency of their reports and facilitate an accurate interpretation of trial results. Improving transparency is particularly important in the context of the replication crisis in science (37).

Despite the publication of the CONSORT Statement extension to NPT trials, the completeness of reporting of NPT trials remains insufficient (38-40). Space constraints in published articles has been suggested as one reason for inadequate reporting of interventions; however, an online appendix or a link to a Web site that provides access to videos and manuals can be used to report this essential information. Open-access repositories, such as the Open Science Framework (https://osf .io), should facilitate dissemination of this information. 


\begin{tabular}{|c|c|c|}
\hline Item & Standard CONSORT Abstract Item & Extension for NPT Trials \\
\hline Title & Identification of the study as randomized & - \\
\hline Authors & Contact details for the corresponding author & - \\
\hline Trial design & $\begin{array}{l}\text { Description of the trial design (e.g. parallel, cluster, } \\
\text { noninferiority) }\end{array}$ & - \\
\hline \multicolumn{3}{|c|}{ - } \\
\hline Participants & $\begin{array}{l}\text { Eligibility criteria for participants and the settings where } \\
\text { the data were collected }\end{array}$ & $\begin{array}{l}\text { When applicable, report eligibility criteria for centers where } \\
\text { the intervention is performed and for care providers }\end{array}$ \\
\hline Interventions & Interventions intended for each group & - \\
\hline Objective & Specific objective or hypothesis & - \\
\hline Outcome & Clearly defined primary outcome for this report & - \\
\hline Randomization & How participants were allocated to interventions & - \\
\hline Blinding (masking) & $\begin{array}{l}\text { Whether or not participants, care givers, and those } \\
\text { assessing the outcomes were blinded to group } \\
\text { assignment }\end{array}$ & - \\
\hline \multicolumn{3}{|c|}{ - } \\
\hline Number randomly assigned & Number of participants randomized to each group & - \\
\hline \multirow[t]{2}{*}{ Recruitment } & Trial status & - \\
\hline & & $\begin{array}{l}\text { Report any important changes to the intervention delivered } \\
\text { from what was planned }\end{array}$ \\
\hline Number analyzed & Number of participants analyzed in each group & - \\
\hline Outcome & $\begin{array}{l}\text { For the primary outcome, a result for each group and } \\
\text { the estimated effect size and its precision }\end{array}$ & - \\
\hline Harms & Important adverse events or side effects & - \\
\hline Conclusions & General interpretation of the results & - \\
\hline Trial registration & Registration number and name of trial register & - \\
\hline Funding & Source of funding & - \\
\hline
\end{tabular}

CONSORT = Consolidated Standards of Reporting Trials; NPT = nonpharmacologic treatment; RCT = randomized controlled trial.

Several initiatives to improve adherence to guidelines have already been implemented (41), most during the submission and peer review process. More recently, use of an online writing aid based on the CONSORT guidelines has shown promising results (42).

The process for developing these guidelines followed recommended practices (43). The updated checklist resulted from a consensus, and some specific issues that were discussed during the meeting, such as difficulties in recruiting in NPT RCTs because of strong investigator and patient preferences, did not lead to changes in the checklist.

Some of the issues considered in this extension can be applied more broadly to the reporting of RCTs assessing such pharmacologic treatments as complex chemotherapy. Finally, the updated checklist is consistent with reporting guidelines that were developed after publication of the 2008 CONSORT extension for NPTs, particularly the TIDieR checklist for better reporting of interventions (22).

We hope the 2017 update of the CONSORT NPT extension improves the reporting of RCTs. The guidelines are not intended to deter authors from publishing imperfect trials-the perfect trial being difficult to achieve-but to ensure transparency and a coherent approach to testing and reporting trials of complex interventions.

From Paris Descartes University, INSERM UMR1153, and Assistance Publique des Hôpitaux de Paris, Paris, France; University of Oxford, Oxford, United Kingdom; Ottawa Hospital Research Institute and University of Ottawa, Ottawa, Ontario, Canada; FHI 360, Durham, North Carolina; University of North Carolina, Chapel Hill, North Carolina; and Columbia University Mailman School of Public Health, New York, New York.

Annals.org
Financial Support: Funding was provided by the research funds of the Centre d'Epidémiologie Clinique, Assistance Publique des Hôpitaux de Paris, and the METHODS Team of the Centre of Research in Epidemiology and Statistics Sorbonne Paris Cité - CRESS-UMR1153.

Disclosures: Dr. Ravaud reports that he is a member of the CONSORT Group, director of EQUATOR France, and a member of the EQUATOR steering group. Authors not named here have disclosed no conflicts of interest. Disclosures can also be viewed at www.acponline.org/authors/icmje/ConflictOfInterest Forms.do?msNum=M17-0046.

Requests for Single Reprints: Isabelle Boutron, $M D, P h D$, Equipe METHODS (CRESS-UMR1153), Centre d'épidémiologie clinique, Hôpital Hôtel-Dieu, 1 place du Parvis Notre-Dame, 75004 Paris, France.

Current author addresses and author contributions are available at Annals.org.

\section{References}

1. Glasziou P, Altman DG, Bossuyt P, Boutron I, Clarke M, Julious S, et al. Reducing waste from incomplete or unusable reports of biomedical research. Lancet. 2014;383:267-76. [PMID: 24411647] doi: 10.1016/S0140-6736(13)62228-X

2. Chalmers I, Glasziou P. Avoidable waste in the production and reporting of research evidence. Lancet. 2009;374:86-9. [PMID: 19525005] doi:10.1016/S0140-6736(09)60329-9

3. Begg C, Cho M, Eastwood S, Horton R, Moher D, Olkin I, et al. Improving the quality of reporting of randomized controlled trials. The CONSORT statement. JAMA. 1996;276:637-9. [PMID: 8773637] 4. Altman DG, Schulz KF, Moher D, Egger M, Davidoff F, Elbourne D, et al; CONSORT Group (Consolidated Standards of Reporting Trials). The revised CONSORT statement for reporting randomized tri- 
als: explanation and elaboration. Ann Intern Med. 2001;134:663-94. [PMID: 11304107] doi:10.7326/0003-4819-134-8-200104170-00012 5. Moher D, Hopewell S, Schulz KF, Montori V, Gøtzsche PC, Devereaux PJ, et al. CONSORT 2010 explanation and elaboration: updated guidelines for reporting parallel group randomised trials. BMJ. 2010;340:c869. [PMID: 20332511] doi:10.1136/bmj.c869

6. Ceelen WP. Clinical research in surgery: threats and opportunities. Eur Surg Res. 2014;53:95-107. [PMID: 25247239] doi:10.1159 1000367606

7. Evrard S, McKelvie-Sebileau $P$, van de Velde $C$, Nordlinger B, Poston G. What can we learn from oncology surgical trials? Nat Rev Clin Oncol. 2016;13:55-62. [PMID: 26483296] doi:10.1038/nrclinonc .2015 .176

8. Boutron I, Tubach F, Giraudeau B, Ravaud P. Methodological differences in clinical trials evaluating nonpharmacological and pharmacological treatments of hip and knee osteoarthritis. JAMA. 2003; 290:1062-70. [PMID: 12941679]

9. Boutron I, Guittet L, Estellat C, Moher D, Hróbjartsson A, Ravaud P. Reporting methods of blinding in randomized trials assessing nonpharmacological treatments. PLoS Med. 2007;4:e61. [PMID: 17311468]

10. Boutron I, Tubach F, Giraudeau B, Ravaud P. Blinding was judged more difficult to achieve and maintain in nonpharmacologic than pharmacologic trials. J Clin Epidemiol. 2004;57:543-50. [PMID: 15246122]

11. Pibouleau L, Boutron I, Reeves BC, Nizard R, Ravaud P. Applicability and generalisability of published results of randomised controlled trials and non-randomised studies evaluating four orthopaedic procedures: methodological systematic review. BMJ. 2009;339: b4538. [PMID: 19920015] doi:10.1136/bmj.b4538

12. Ergina PL, Cook JA, Blazeby JM, Boutron I, Clavien PA, Reeves $\mathrm{BC}$, et al; Balliol Collaboration. Challenges in evaluating surgical innovation. Lancet. 2009;374:1097-104. [PMID: 19782875] doi:10 .1016/S0140-6736(09)61086-2

13. Cook JA. The challenges faced in the design, conduct and analysis of surgical randomised controlled trials. Trials. 2009;10:9. [PMID: 19200379] doi:10.1186/1745-6215-10-9

14. McCulloch P, Altman DG, Campbell WB, Flum DR, Glasziou P, Marshall JC, et al; Balliol Collaboration. No surgical innovation without evaluation: the IDEAL recommendations. Lancet. 2009;374: 1105-12. [PMID: 19782876] doi:10.1016/S0140-6736(09)61116-8 15. Boutron I, Moher D, Altman DG, Schulz KF, Ravaud P; CONSORT Group. Extending the CONSORT statement to randomized trials of nonpharmacologic treatment: explanation and elaboration. Ann Intern Med. 2008;148:295-309. [PMID: 18283207] doi:10.7326/0003 -4819-148-4-200802190-00008

16. Boutron I, Moher D, Altman DG, Schulz KF, Ravaud P; CONSORT Group. Methods and processes of the CONSORT Group: example of an extension for trials assessing nonpharmacologic treatments. Ann Intern Med. 2008;148:W60-6. [PMID: 18283201] doi:10.7326/0003 -4819-148-4-200802190-00008-w1

17. Schulz KF, Altman DG, Moher D; CONSORT Group. CONSORT 2010 statement: updated guidelines for reporting parallel group randomised trials. PLoS Med. 2010;7:e1000251. [PMID: 20352064] doi:10.1371/journal.pmed.1000251

18. Hopewell S, Clarke M, Moher D, Wager E, Middleton P, Altman DG, et al; CONSORT Group. CONSORT for reporting randomised trials in journal and conference abstracts. Lancet. 2008;371:281-3. [PMID: 18221781] doi:10.1016/S0140-6736(07)61835-2

19. Hopewell S, Clarke M, Moher D, Wager E, Middleton P, Altman DG, et al; CONSORT Group. CONSORT for reporting randomized controlled trials in journal and conference abstracts: explanation and elaboration. PLoS Med. 2008;5:e20. [PMID: 18215107] doi:10.1371/ journal.pmed.0050020

20. Moore GF, Audrey S, Barker M, Bond L, Bonell C, Hardeman W, et al. Process evaluation of complex interventions: Medical Research Council guidance. BMJ. 2015;350:h1258. [PMID: 25791983] doi:10 $.1136 / \mathrm{bmj} . \mathrm{h} 1258$
21. Blencowe NS, Blazeby JM, Donovan JL, Mills N. Novel ways to explore surgical interventions in randomised controlled trials: applying case study methodology in the operating theatre. Trials. 2015; 16:589. [PMID: 26710760] doi:10.1186/s13063-015-1127-x

22. Hoffmann TC, Glasziou PP, Boutron I, Milne R, Perera R, Moher $D$, et al. Better reporting of interventions: Template for Intervention Description and Replication (TIDieR) checklist and guide. BMJ. 2014; 348:g1687. [PMID: 24609605] doi:10.1136/bmj.g1687

23. Halm EA, Lee $C$, Chassin MR. Is volume related to outcome in health care? A systematic review and methodologic critique of the literature. Ann Intern Med. 2002;137:511-20. [PMID: 12230353] 24. Cook JA, Bruckner T, MacLennan GS, Seiler CM. Clustering in surgical trials-database of intracluster correlations. Trials. 2012;13:2. [PMID: 22217216] doi:10.1186/1745-6215-13-2

25. Roberts C, Roberts SA. Design and analysis of clinical trials with clustering effects due to treatment. Clin Trials. 2005;2:152-62. [PMID: 16279137]

26. Kahan BC, Morris TP. Assessing potential sources of clustering in individually randomised trials. BMC Med Res Methodol. 2013;13:58. [PMID: 23590245] doi:10.1186/1471-2288-13-58

27. Lee KJ, Thompson SG. Clustering by health professional in individually randomised trials. BMJ. 2005;330:142-4. [PMID: 15649931] 28. Roberts C, Walwyn R. Design and analysis of nonpharmacological treatment trials with multiple therapists per patient. Stat Med. 2013;32:81-98. [PMID: 22865729] doi:10.1002/sim.5521 29. Roberts $C$. The implications of variation in outcome between health professionals for the design and analysis of randomized controlled trials. Stat Med. 1999;18:2605-15. [PMID: 10495459]

30. Lee KJ, Thompson SG. The use of random effects models to allow for clustering in individually randomized trials. Clin Trials. 2005; 2:163-73. [PMID: 16279138]

31. Wartolowska K, Judge A, Hopewell S, Collins GS, Dean BJ, Rombach I, et al. Use of placebo controls in the evaluation of surgery: systematic review. BMJ. 2014;348:g3253. [PMID: 24850821] doi:10 $.1136 / \mathrm{bmj} . \mathrm{g} 3253$

32. Torgerson D. Designing Randomised Trials in Health, Education and the Social Sciences. An Introduction. London: Palgrave Macmillan UK; 2008.

33. Thornton JG, Hornbuckle J, Vail A, Spiegelhalter DJ, Levene $M_{i}$ GRIT study group. Infant wellbeing at 2 years of age in the Growth Restriction Intervention Trial (GRIT): multicentred randomised controlled trial. Lancet. 2004;364:513-20. [PMID: 15302194]

34. Burton AK, Tillotson KM, Cleary J. Single-blind randomised controlled trial of chemonucleolysis and manipulation in the treatment of symptomatic lumbar disc herniation. Eur Spine J. 2000;9:202-7. [PMID: 10905437]

35. Hoffmann TC, Erueti C, Glasziou PP. Poor description of nonpharmacological interventions: analysis of consecutive sample of randomised trials. BMJ. 2013;347:f3755. [PMID: 24021722] doi:10 $.1136 / \mathrm{bmj} . \mathrm{f3755}$

36. Nagendran M, Harding D, Teo W, Camm C, Maruthappu M, McCulloch $\mathrm{P}$, et al. Poor adherence of randomised trials in surgery to CONSORT guidelines for non-pharmacological treatments (NPT): a cross-sectional study. BMJ Open. 2013;3:e003898. [PMID: 24353256] doi:10.1136/bmjopen-2013-003898

37. Baker M. 1,500 scientists lift the lid on reproducibility. Nature. 2016:533:452-4. [PMID: 27225100] doi:10.1038/533452a

38. Dworkin JD, McKeown A, Farrar JT, Gilron I, Hunsinger M, Kerns $R D$, et al. Deficiencies in reporting of statistical methodology in recent randomized trials of nonpharmacologic pain treatments: ACTTION systematic review. J Clin Epidemiol. 2016;72:56-65. [PMID: 26597977] doi:10.1016/j.jclinepi.2015.10.019

39. Yu J, Li X, Li Y, Sun X. Quality of reporting in surgical randomized clinical trials. Br J Surg. 2017;104:296-303. [PMID: 27918069] doi:10 $.1002 /$ bjs. 10331

40. McCleary N, Duncan EM, Stewart F, Francis JJ. Active ingredients are reported more often for pharmacologic than nonpharmacologic interventions: an illustrative review of reporting practices in titles and abstracts. Trials. 2013;14:146. [PMID: 23688143] doi:10.1186/1745-6215-14-146 
41. Chan L, Heinemann AW, Roberts J. Elevating the quality of disability and rehabilitation research: mandatory use of the reporting guidelines [Editorial]. Arch Phys Med Rehabil. 2014;95:415-7. [PMID: 24559651] doi:10.1016/j.apmr.2013.12.010

42. Barnes C, Boutron I, Giraudeau B, Porcher R, Altman DG, Ravaud

$\mathrm{P}$. Impact of an online writing aid tool for writing a randomized trial report: the COBWEB (Consort-based WEB tool) randomized controlled trial. BMC Med. 2015;13:221. [PMID: 26370288] doi:10.1186 /s12916-015-0460-y

43. Moher D, Schulz KF, Simera I, Altman DG. Guidance for developers of health research reporting guidelines. PLoS Med. 2010;7: e1000217. [PMID: 20169112] doi:10.1371/journal.pmed.1000217

\section{Annals Consult Guys: Learn and laugh with Annals' video-based CME feature.}

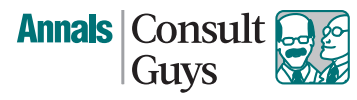

Annals Consult Guys bring a new perspective to the art and science of medicine with lively discussion and analysis of real-world cases and situations.

The videos are available to everyone, and ACP Members and Annals subscribers can earn .5 AMA PRA Category 1 Credit per video.

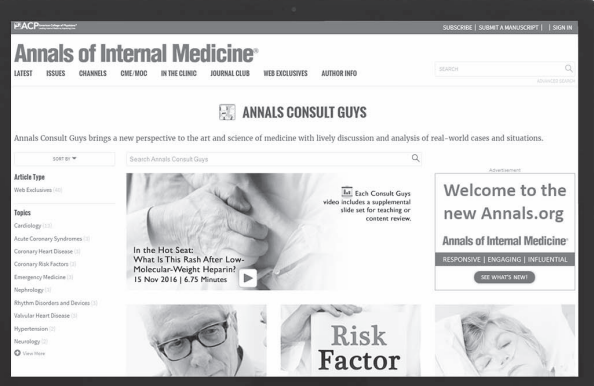

For more videos from and information on Annals Consult Guys, visit www.annals.org/ConsultGuys.

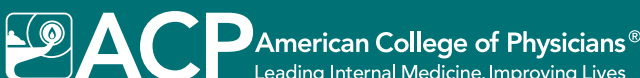


Current Author Addresses: Drs. Boutron and Ravaud: Equipe METHODS (CRESS-UMR1153), Centre d'épidémiologie clinique, Hôpital Hôtel-Dieu, 1 place du Parvis Notre-Dame, 75004 Paris, France.

Dr. Altman: Centre for Statistics in Medicine, Nuffield Department of Orthopaedics, Rheumatology and Musculoskeletal Sciences, University of Oxford, Botnar Research Centre, Windmill Road, Oxford OX3 7LD, United Kingdom.

Dr. Moher: Centre for Journalology, Ottawa Hospital Research Institute, The Ottawa Hospital, General Campus, 501 Smyth Road, Room L1288, Ottawa, Ontario K1H 8L6, Canada.

Dr. Schulz: FHI 360, 359 Blackwell Street, Suite 200, Durham, NC 27701.

Author Contributions: Conception and design: I. Boutron, D.G. Altman, D. Moher, K.F. Schulz, P. Ravaud.

Analysis and interpretation of the data: I. Boutron, D.G. Altman, D. Moher, P. Ravaud.

Drafting of the article: I. Boutron, D. Moher, P. Ravaud.

Critical revision of the article for important intellectual content: I. Boutron, D.G. Altman, D. Moher, K.F. Schulz, P. Ravaud. Final approval of the article: I. Boutron, D.G. Altman, D. Moher, K.F. Schulz, P. Ravaud.

Statistical expertise: D.G. Altman, K.F. Schulz.

Obtaining of funding: P. Ravaud.

Administrative, technical, or logistic support: P. Ravaud.

Collection and assembly of data: I. Boutron, D. Moher, P. Ravaud.

\section{APPENDIX 1: CONSORT NPT GROUP}

The following members of the CONSORT NPT Group contributed to the article but did not author it:

Virginia Barbour (Office of Research Ethics \& Integrity and Division of Research and Commercialisation, Queensland University of Technology, Brisbane, Queensland, Australia)

Kamaldeep Bhui (Centre for Psychiatry, Wolfson Institute of Preventive Medicine, Barts and the London School of Medicine and Dentistry, Queen Mary University of London, London, United Kingdom)

Nancy Chescheir (University of North Carolina at Chapel Hill Department of Obstetrics and Gynecology, Chapel Hill, North Carolina)

Pierre Alain Clavien (Department of Surgery, Swiss HPB and Transplantation Center, Department of Surgery, University Hospital Zürich, Zürich, Switzerland)

Markus K. Diener (Department of General, Visceral, and Transplantation Surgery; Study Center of the German Surgical Society, University of Heidelberg, Heidelberg, Germany)

Paul Glasziou (Centre for Research in Evidence Based Practice, Bond University, Robina, Queensland, Australia)

Robert M. Golub (JAMA)

Jeremy M. Grimshaw (Centre for PracticeChanging Research, Ottawa Hospital Research Institute; Department of Medicine, University of Ottawa, Ottawa, Ontario, Canada)
Trish Groves (British Medical Journal)

Sally Hopewell (Centre for Rehabilitation Research in Oxford, Nuffield Department of Orthopaedics, Rheumatology and Musculoskeletal Sciences, University of Oxford, Oxford, United Kingdom)

Sarah E. Lamb (Centre for Rehabilitation Research in Oxford, Nuffield Department of Orthopaedics, Rheumatology and Musculoskeletal Sciences, University of Oxford, Oxford, United Kingdom)

Peter McCulloch (Nuffield Department of Surgical Sciences, University of Oxford, Oxford, United Kingdom)

Cynthia Mulrow (Annals of Internal Medicine; University of Texas Health Science Center, San Antonio, Texas)

Daniel Riddle (Virginia Commonwealth University, Richmond, Virginia)

Joseph S. Ross (General Internal Medicine, School of Medicine and Health Policy and Management, School of Public Health, Yale University, New Haven, Connecticut)

Paula P. Schnurr (National Center for PTSD, White River Junction, Vermont; Geisel School of Medicine at Dartmouth, Hanover, New Hampshire)

David Schriger (University of California, Los Angeles, Los Angeles, California)

Larissa Shamseer (Centre for Practice-Changing Research, Ottawa Hospital Research Institute; School of Epidemiology, Public Health and Preventative Medicine, University of Ottawa, Ottawa, Ontario, Canada)

David Torgerson (York Trials Unit, Department of Health Sciences, University of York, York, United Kingdom)

\section{Appendix 2: Literature SeArCh}

We searched for studies evaluating adherence to the CONSORT NPT extension and methodological developments that we should consider in the update. We searched Web of Science (search date, November 2013; update, July 2016) to identify all published articles citing 1 of the 2 articles on the 2008 CONSORT NPT extension $(15,16)$. We also searched MEDLINE via PubMed for studies evaluating the reporting of trials assessing NPTs since January 2009 (search date, November 2013; update, July 2016) by using the following search strategy: (Reporting AND CONSORT)[tiab], with a limitation to articles that had an abstract and were published in English. Finally, we used a personal collection of reports on new developments related to the specific methodological issues when assessing NPTs (for example, clustering within individual-patient RCTs or complexity of the intervention) and other relevant reporting guidelines developed since the publication of the 2008 CONSORT extension for NPTs, such as 
the TIDieR checklist developed to report all types of interventions (22).

\section{Web-Only References}

44. Frutos MD, Abrisqueta J, Lujan J, Abellan I, Parrilla P. Randomized prospective study to compare laparoscopic appendectomy versus umbilical single-incision appendectomy. Ann Surg. 2013;257: 413-8. [PMID: 23386239] doi:10.1097/SLA.0b013e318278d225 45. Wyrsch B, McFerran MA, McAndrew M, Limbird TJ, Harper MC, Johnson KD, et al. Operative treatment of fractures of the tibial plafond. A randomized, prospective study. J Bone Joint Surg Am. 1996; 78:1646-57. [PMID: 8934478]

46. Linehan MM, Comtois KA, Murray AM, Brown MZ, Gallop RJ, Heard HL, et al. Two-year randomized controlled trial and follow-up of dialectical behavior therapy vs therapy by experts for suicidal behaviors and borderline personality disorder. Arch Gen Psychiatry. 2006:63:757-66. [PMID: 16818865]

47. Molyneux A, Kerr R, Stratton I, Sandercock P, Clarke M, Shrimpton J, et al; International Subarachnoid Aneurysm Trial (ISAT) Collaborative Group. International Subarachnoid Aneurysm Trial (ISAT) of neurosurgical clipping versus endovascular coiling in 2143 patients with ruptured intracranial aneurysms: a randomised trial. Lancet. 2002;360:1267-74. [PMID: 12414200]

48. Bonjer HJ, Deijen CL, Abis GA, Cuesta MA, van der Pas MH, de Lange-de Klerk ES, et al; COLOR II Study Group. A randomized trial of laparoscopic versus open surgery for rectal cancer. N Engl J Med. 2015:372:1324-32. [PMID: 25830422] doi:10.1056/NEJMoa141 4882

49. Zaidat OO, Fitzsimmons BF, Woodward BK, Wang Z, KillerOberpfalzer M, Wakhloo A, et al; VISSIT Trial Investigators. Effect of a balloon-expandable intracranial stent vs medical therapy on risk of stroke in patients with symptomatic intracranial stenosis: the VISSIT randomized clinical trial. JAMA. 2015;313:1240-8. [PMID: 25803346] doi:10.1001/jama.2015.1693

50. Lamb SE, Williamson EM, Heine PJ, Adams J, Dosanjh S, Dritsaki $M$, et al; Strengthening and Stretching for Rheumatoid Arthritis of the Hand Trial (SARAH) Trial Team. Exercises to improve function of the rheumatoid hand (SARAH): a randomised controlled trial. Lancet. 2015;385:421-9. [PMID: 25308290] doi:10.1016/S0140-6736(14) 60998-3

51. Freedland KE, Carney RM, Rich MW, Steinmeyer BC, Rubin EH. Cognitive behavior therapy for depression and self-care in heart failure patients: a randomized clinical trial. JAMA Intern Med. 2015:175: 1773-82. [PMID: 26414759] doi:10.1001/jamainternmed.2015.5220 52. Willett K, Keene DJ, Mistry D, Nam J, Tutton E, Handley R, et al; Ankle Injury Management (AIM) Trial Collaborators. Close contact casting vs surgery for initial treatment of unstable ankle fractures in older adults: a randomized clinical trial. JAMA. 2016;316:1455-1463. [PMID: 27727383] doi:10.1001/jama.2016.14719

53. Wiegersma M, Panman CM, Kollen BJ, Berger MY, Lisman-Van Leeuwen Y, Dekker JH. Effect of pelvic floor muscle training compared with watchful waiting in older women with symptomatic mild pelvic organ prolapse: randomised controlled trial in primary care. BMJ. 2014;349:g7378. [PMID: 25533442] doi:10.1136/bmj.g7378

54. Bronfort G, Hondras MA, Schulz CA, Evans RL, Long CR, Grimm R. Spinal manipulation and home exercise with advice for subacute and chronic back-related leg pain: a trial with adaptive allocation. Ann Intern Med. 2014:161:381-91. [PMID: 25222385] doi:10.7326 /M14-0006

55. Friedli K, King MB, Lloyd M, Horder J. Randomised controlled assessment of non-directive psychotherapy versus routine generalpractitioner care. Lancet. 1997;350:1662-5. [PMID: 9400510]

56. Rintoul RC, Ritchie AJ, Edwards JG, Waller DA, Coonar AS, Bennett $M$, et al; MesoVATS Collaborators. Efficacy and cost of videoassisted thoracoscopic partial pleurectomy versus talc pleurodesis in patients with malignant pleural mesothelioma (MesoVATS): an openlabel, randomised, controlled trial. Lancet. 2014;384:1118-27. [PMID: 24942631] doi:10.1016/S0140-6736(14)60418-9

57. Droeser RA, Dell-Kuster S, Kurmann A, Rosenthal R, Zuber M, Metzger J, et al. Long-term follow-up of a randomized controlled trial of Lichtenstein's operation versus mesh plug repair for inguinal hernia. Ann Surg. 2014;259:966-72. [PMID: 24169195] doi:10.1097 /SLA.0000000000000297

58. Van Buren G 2nd, Bloomston M, Hughes SJ, Winter J, Behrman SW, Zyromski NJ, et al. A randomized prospective multicenter trial of pancreaticoduodenectomy with and without routine intraperitoneal drainage. Ann Surg. 2014;259:605-12. [PMID: 24374513] doi:10 .1097/SLA.0000000000000460

59. Feldon SE, Scherer RW, Hooper FJ, Kelman S, Baker RS, Granadier RJ, et al; Ischemic Optic Neuropathy Decompression Trial Research Group. Surgical quality assurance in the Ischemic Optic Neuropathy Decompression Trial (IONDT). Control Clin Trials. 2003;24: 294-305. [PMID: 12757995]

60. Winstein CJ, Wolf SL, Dromerick AW, Lane CJ, Nelsen MA, Lewthwaite R, et al; Interdisciplinary Comprehensive Arm Rehabilitation Evaluation (ICARE) Investigative Team. Effect of a taskoriented rehabilitation program on upper extremity recovery following motor stroke: the ICARE randomized clinical trial. JAMA. 2016 315:571-81. [PMID: 26864411] doi:10.1001/jama.2016.0276 61. Guillou PJ, Quirke P, Thorpe H, Walker J, Jayne DG, Smith AM, et al; MRC CLASICC trial group. Short-term endpoints of conventional versus laparoscopic-assisted surgery in patients with colorectal cancer (MRC CLASICC trial): multicentre, randomised controlled trial. Lancet. 2005;365:1718-26. [PMID: 15894098]

62. Weeks JC, Nelson H, Gelber S, Sargent D, Schroeder G; Clinical Outcomes of Surgical Therapy (COST) Study Group. Short-term quality-of-life outcomes following laparoscopic-assisted colectomy vs open colectomy for colon cancer: a randomized trial. JAMA 2002;287:321-8. [PMID: 11790211]

63. Foa EB, McLean CP, Capaldi S, Rosenfield D. Prolonged exposure vs supportive counseling for sexual abuse-related PTSD in adolescent girls: a randomized clinical trial. JAMA. 2013;310:2650-7. [PMID: 24368465] doi:10.1001/jama.2013.282829

64. Schnurr PP, Friedman MJ, Engel CC, Foa EB, Shea MT, Resick $\mathrm{PM}$, et al. Issues in the design of multisite clinical trials of psychotherapy: VA Cooperative Study No. 494 as an example. Contemp Clin Trials. 2005;26:626-36. [PMID: 16236558]

65. Rogers CA, Pike K, Campbell H, Reeves BC, Angelini GD, Gray $A$, et al; CRISP investigators. Coronary artery bypass grafting in highRISk patients randomised to off- or on-Pump surgery: a randomised controlled trial (the CRISP trial). Health Technol Assess. 2014;18:v-xx 1-157. [PMID: 25023641] doi:10.3310/hta18440

66. Schnurr PP, Chard KM, Ruzek JI, Chow BK, Shih MC, Resick PA, et al. Design of VA Cooperative Study \#591: CERV-PTSD, comparative effectiveness research in veterans with PTSD. Contemp Clin Trials. 2015;41:75-84. [PMID: 25457792] doi:10.1016/j.cct.2014.11.017 67. Costa ML, Achten J, Parsons NR, Rangan A, Griffin D, Tubeuf S, et al; DRAFFT Study Group. Percutaneous fixation with Kirschner wires versus volar locking plate fixation in adults with dorsally displaced fracture of distal radius: randomised controlled trial. BMJ. 2014;349:g4807. [PMID: 25096595] doi:10.1136/bmj.g4807

68. Duroy D, Boutron I, Baron G, Ravaud P, Estellat C, Lejoyeux M. Impact of a computer-assisted Screening, Brief Intervention and Referral to Treatment on reducing alcohol consumption among patients with hazardous drinking disorder in hospital emergency departments. The randomized BREVALCO trial. Drug Alcohol Depend. 2016;165:236-44. [PMID: 27370526] doi:10.1016/j.drugalcdep.2016 .06 .018

69. Cohen A, Assyag P, Boyer-Chatenet L, Cohen-Solal A, Perdrix C Dalichampt $M$, et al; Réseau Insuffisance Cardiaque (RESICARD) PREVENTION Investigators. An education program for risk factor management after an acute coronary syndrome: a randomized clinical trial. JAMA Intern Med. 2014;174:40-8. [PMID: 24126705] doi:10 1001/jamainternmed.2013.11342

70. Taggart DP, Altman DG, Gray AM, Lees B, Nugara F, Yu LM, et al; ART Investigators. Effects of on-pump and off-pump surgery in the Arterial Revascularization Trial. Eur J Cardiothorac Surg. 2015;47: 1059-65. [PMID: 25217501] doi:10.1093/ejcts/ezu349

71. Klaber Moffett JA, Jackson DA, Richmond S, Hahn S, Coulton S, Farrin $A$, et al. Randomised trial of a brief physiotherapy intervention 
compared with usual physiotherapy for neck pain patients: outcomes and patients' preference. BMJ. 2005;330:75. [PMID: 15585539]

72. SoS Investigators. Coronary artery bypass surgery versus percutaneous coronary intervention with stent implantation in patients with multivessel coronary artery disease (the Stent or Surgery trial): a randomised controlled trial. Lancet. 2002;360:965-70. [PMID: 12383664]

73. Eker HH, Hansson BM, Buunen M, Janssen IM, Pierik RE, Hop WC, et al. Laparoscopic vs. open incisional hernia repair: a randomized clinical trial. JAMA Surg. 2013;148:259-63. [PMID: 23552714] doi:10.1001/jamasurg.2013.1466

74. Delitto A, Piva SR, Moore CG, Fritz JM, Wisniewski SR, Josbeno $D A$, et al. Surgery versus nonsurgical treatment of lumbar spinal stenosis: a randomized trial. Ann Intern Med. 2015;162:465-73. [PMID: 25844995] doi:10.7326/M14-1420

75. Neumayer LA, Gawande AA, Wang J, Giobbie-Hurder A, Itani KM, Fitzgibbons RJ Jr, et al; CSP \#456 Investigators. Proficiency of surgeons in inguinal hernia repair: effect of experience and age. Ann Surg. 2005;242:344-8. [PMID: 16135920]

76. Shear K, Frank E, Houck PR, Reynolds CF 3rd. Treatment of complicated grief: a randomized controlled trial. JAMA. 2005;293: 2601-8. [PMID: 15928281]

77. Wright JG, Wang EE, Owen JL, Stephens D, Graham HK, Hanlon $M$, et al. Treatments for paediatric femoral fractures: a randomised trial. Lancet. 2005;365:1153-8. [PMID: 15794970]

78. Linde K, Streng A, Jürgens S, Hoppe A, Brinkhaus B, Witt C, et al. Acupuncture for patients with migraine: a randomized controlled trial. JAMA. 2005;293:2118-25. [PMID: 15870415]

79. Moseley JB, O'Malley K, Petersen NJ, Menke TJ, Brody BA, Kuykendall $\mathrm{DH}$, et al. A controlled trial of arthroscopic surgery for osteoarthritis of the knee. N Engl J Med. 2002;347:81-8. [PMID: 12110735]
80. Hupperets MD, Verhagen EA, van Mechelen W. Effect of unsupervised home based proprioceptive training on recurrences of ankle sprain: randomised controlled trial. BMJ. 2009;339:b2684 [PMID: 19589822] doi:10.1136/bmj.b2684

81. Kutner JS, Smith MC, Corbin L, Hemphill L, Benton K, Mellis BK, et al. Massage therapy versus simple touch to improve pain and mood in patients with advanced cancer: a randomized trial. Ann Intern Med. 2008;149:369-79. [PMID: 18794556] doi:10.7326/00034819-149-6-200809160-00003

82. Keogh-Brown MR, Bachmann MO, Shepstone L, Hewitt C, Howe A, Ramsay CR, et al. Contamination in trials of educational interventions. Health Technol Assess. 2007;11:iii, ix-107. [PMID: 17935683] 83. Cook JA, Elders A, Boachie C, Bassinga T, Fraser C, Altman DG, et al. A systematic review of the use of an expertise-based randomised controlled trial design. Trials. 2015;16:241. [PMID: 26025450] doi:10.1186/s13063-015-0739-5

84. Devereaux PJ, Bhandari M, Clarke M, Montori VM, Cook DJ, Yusuf S, et al. Need for expertise based randomised controlled trials. BMJ. 2005;330:88. [PMID: 15637373]

85. Walter SD, Ismaila AS, Devereaux PJ; SPRINT Study Investigators. Statistical issues in the design and analysis of expertise-based randomized clinical trials. Stat Med. 2008;27:6583-96. [PMID: 18837074] doi:10.1002/sim.3448

86. Pike K, Angelini GD, Reeves BC, Taggart DP, Rogers CA. Recruitment challenges in surgical trials: lessons from the CRISP trial. Trials. 2013;14(Suppl 1):P27. doi:10.1186/1745-6215-14-S1-P27

87. Menon M, Muhletaler F, Campos M, Peabody JO. Assessment of early continence after reconstruction of the periprostatic tissues in patients undergoing computer assisted (robotic) prostatectomy: results of a 2 group parallel randomized controlled trial. J Urol. 2008; 180:1018-23. [PMID: 18639300] doi:10.1016/j.juro.2008.05.046 


\begin{tabular}{lc}
\hline \multicolumn{2}{l}{ Appendix Table 1. Characteristics of Corresponding } \\
Authors Surveyed About the CONSORT Statement \\
Extension for RCTs of NPTs $(n=194)^{*}$ & Value \\
\hline Characteristic & \\
\hline Domain of expertise, \% & 23 \\
Surgery & 4 \\
Devices & 24 \\
Rehabilitation & 8 \\
Psychotherapy & 20 \\
Behavioral interventions & 21 \\
Other & \\
Location, \% & 54 \\
Europe & 22 \\
United States & 9 \\
Canada & 3 \\
South America & 3 \\
Asia & 10 \\
Oceania & $9.6(30.5)$ \\
Mean RCTs participants had been involved in (SD), $n$ & $3.8(7.0)$ \\
Mean reports of RCTs published (SD), $n$ & $2.8(3.7)$ \\
Mean reports of RCTs evaluating NPTs published (SD), $n$ & 40 \\
Use of CONSORT extension for NPT trials, \% & \\
\hline
\end{tabular}

CONSORT $=$ Consolidated Standards of Reporting Trials; NPT $=$ nonpharmacologic treatment; $\mathrm{RCT}=$ randomized controlled trial.

* Response rate was $13 \%$ (194 of 1525).

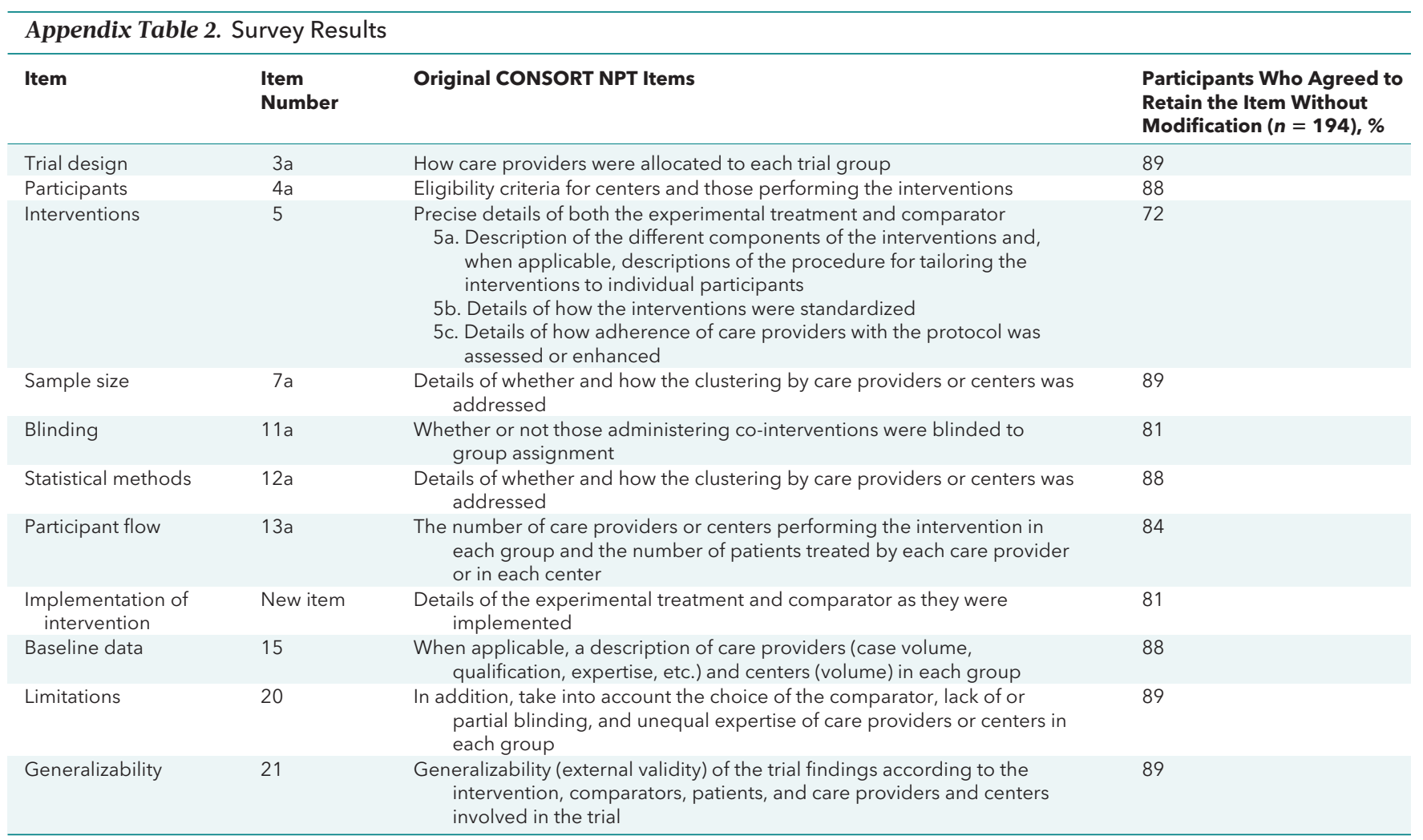

CONSORT $=$ Consolidated Standards of Reporting Trials; NPT = nonpharmacologic treatment. 

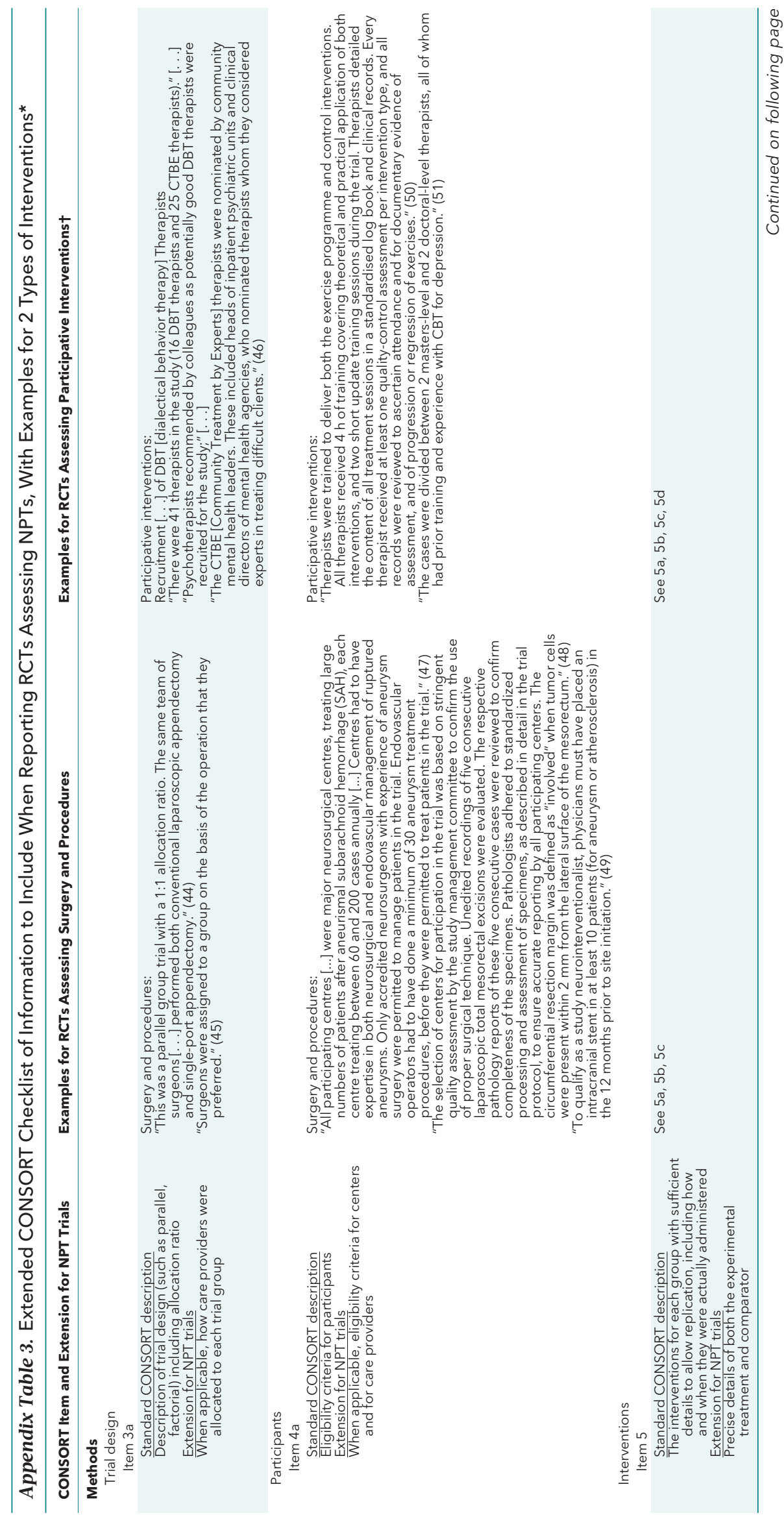

Annals.org
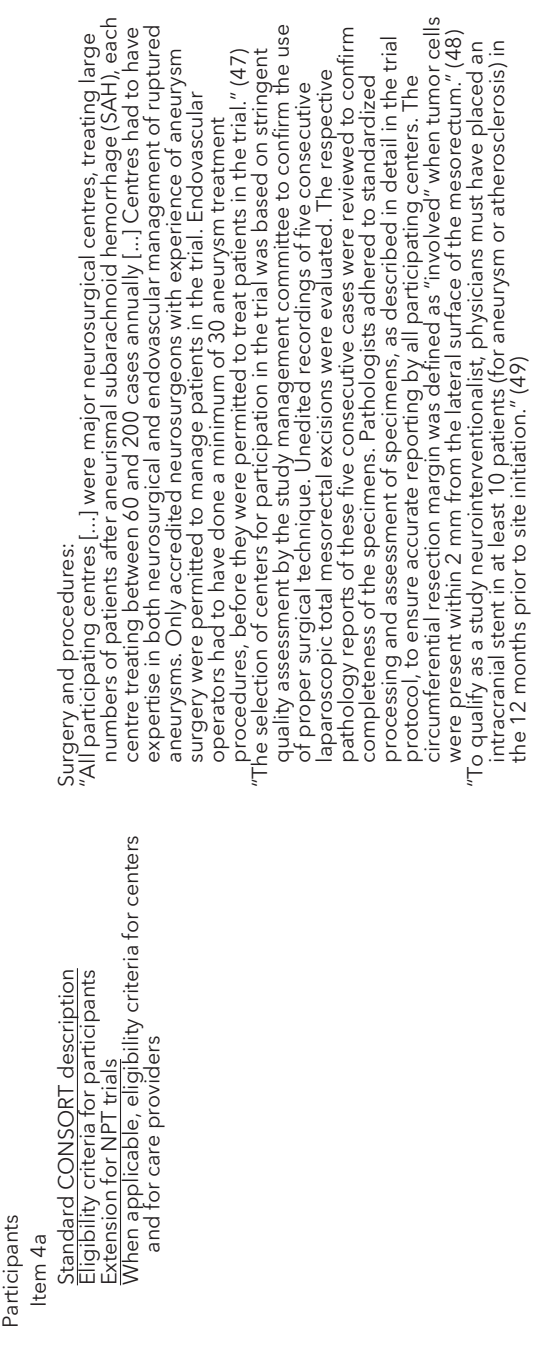

Downloaded from https://annals.org by Univ of North Carolina user on 08/13/2019 


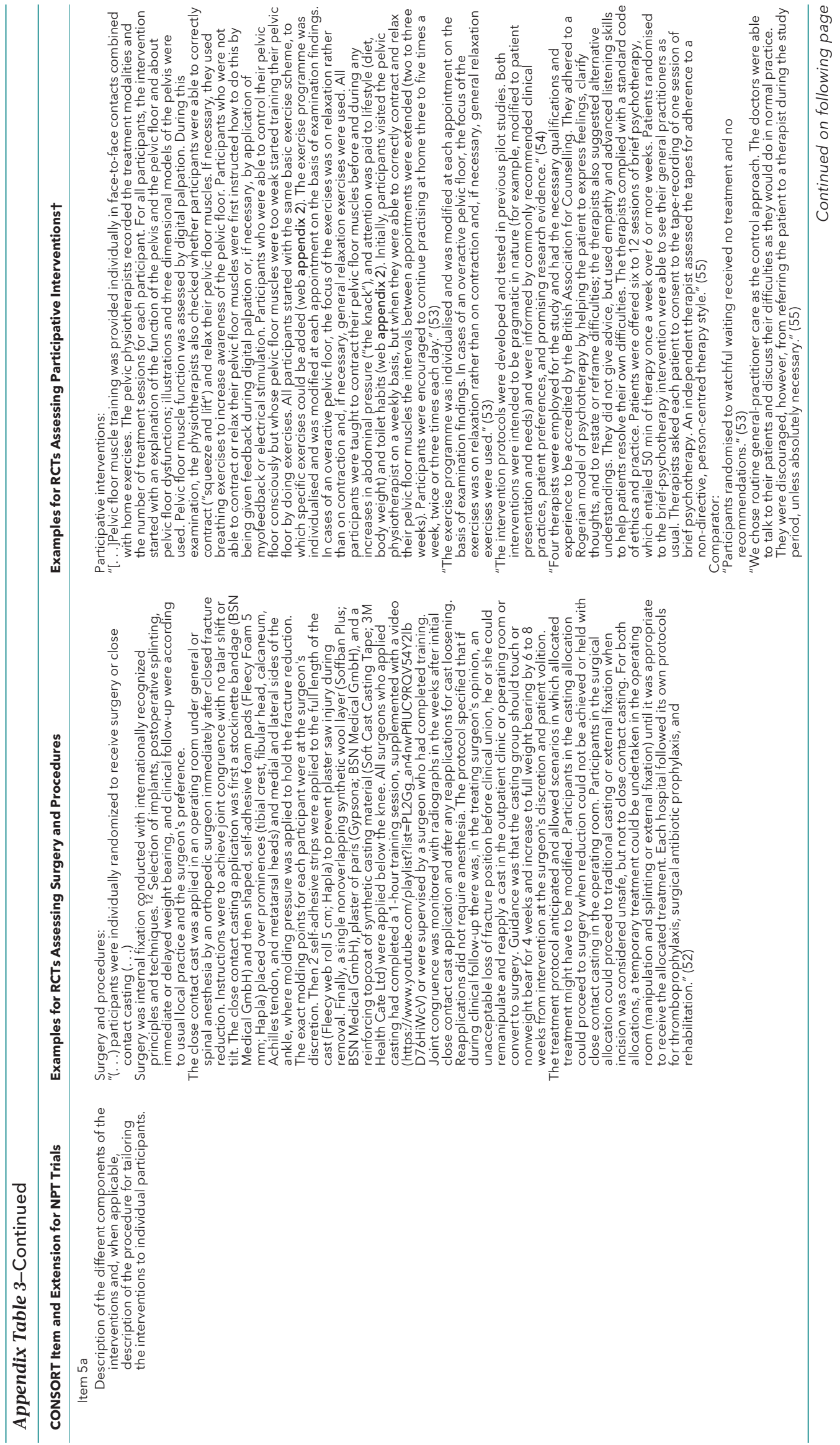






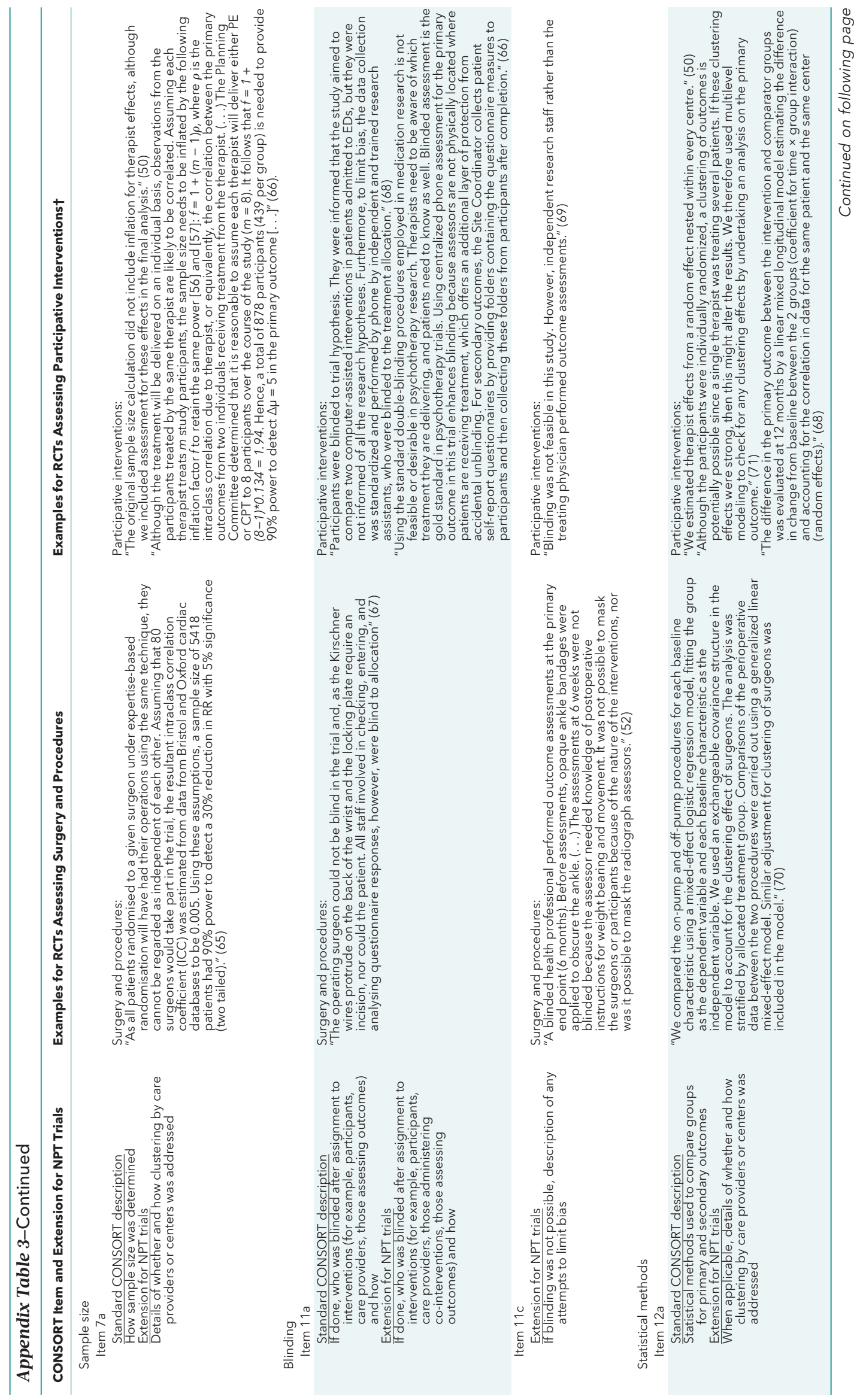



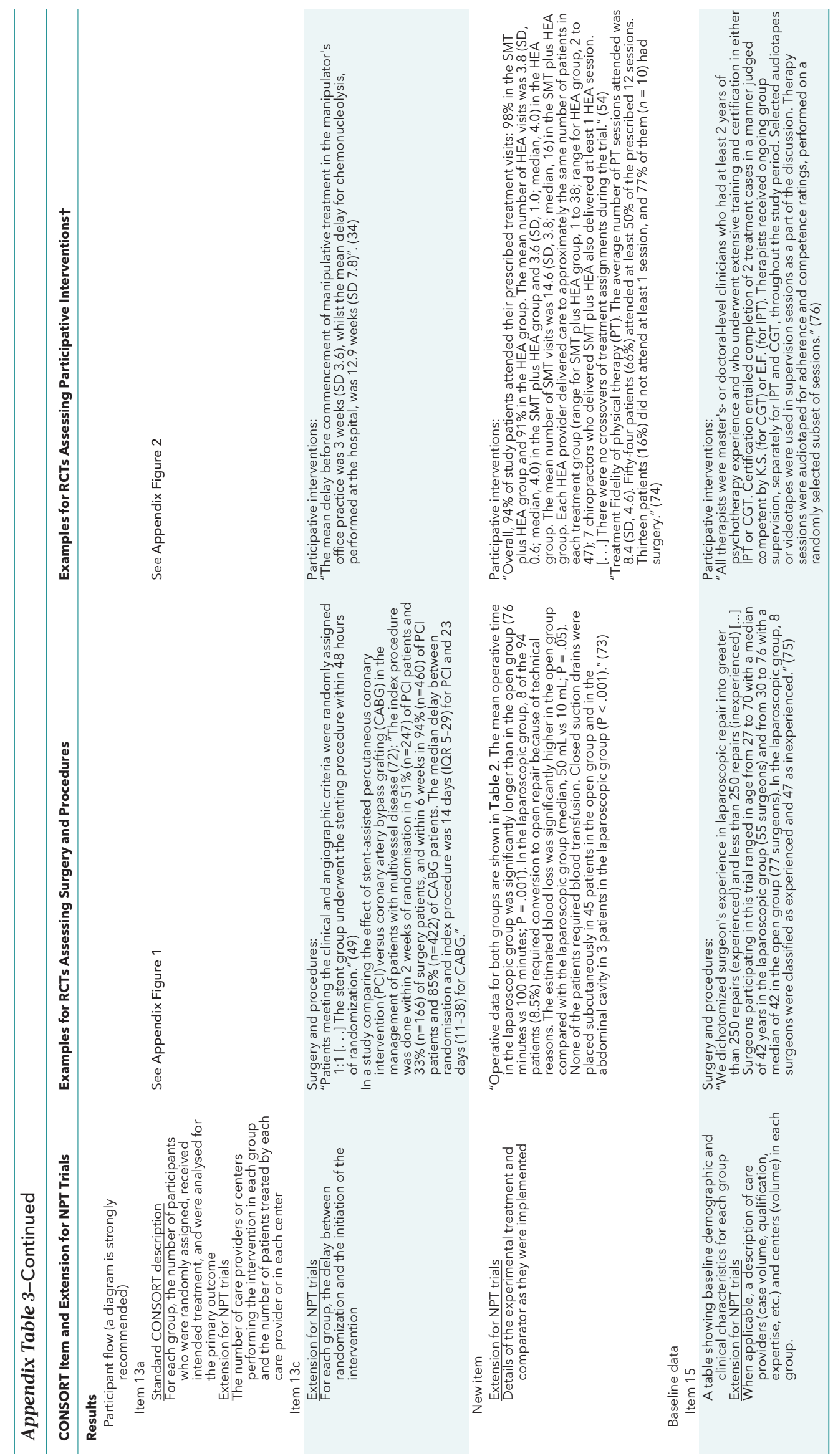

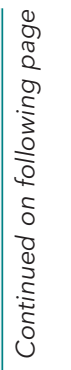

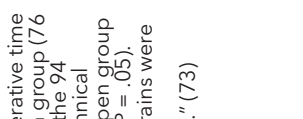

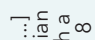

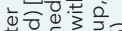

ब过 б. 웡응ㅇㅇㅇ = $\mathrm{x}$ 응

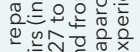
눙 응 잉ㅇㅇㅢ

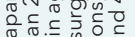

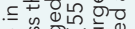

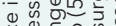

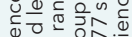

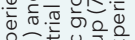

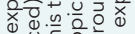

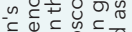
o. is 言言选

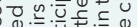
हैं

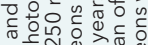

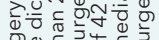
范 O.
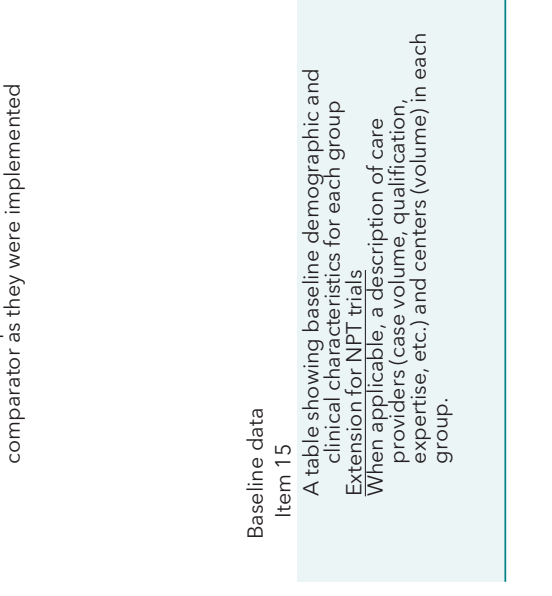

Downloaded from https://annals.org by Univ of North Carolina user on 08/13/2019 


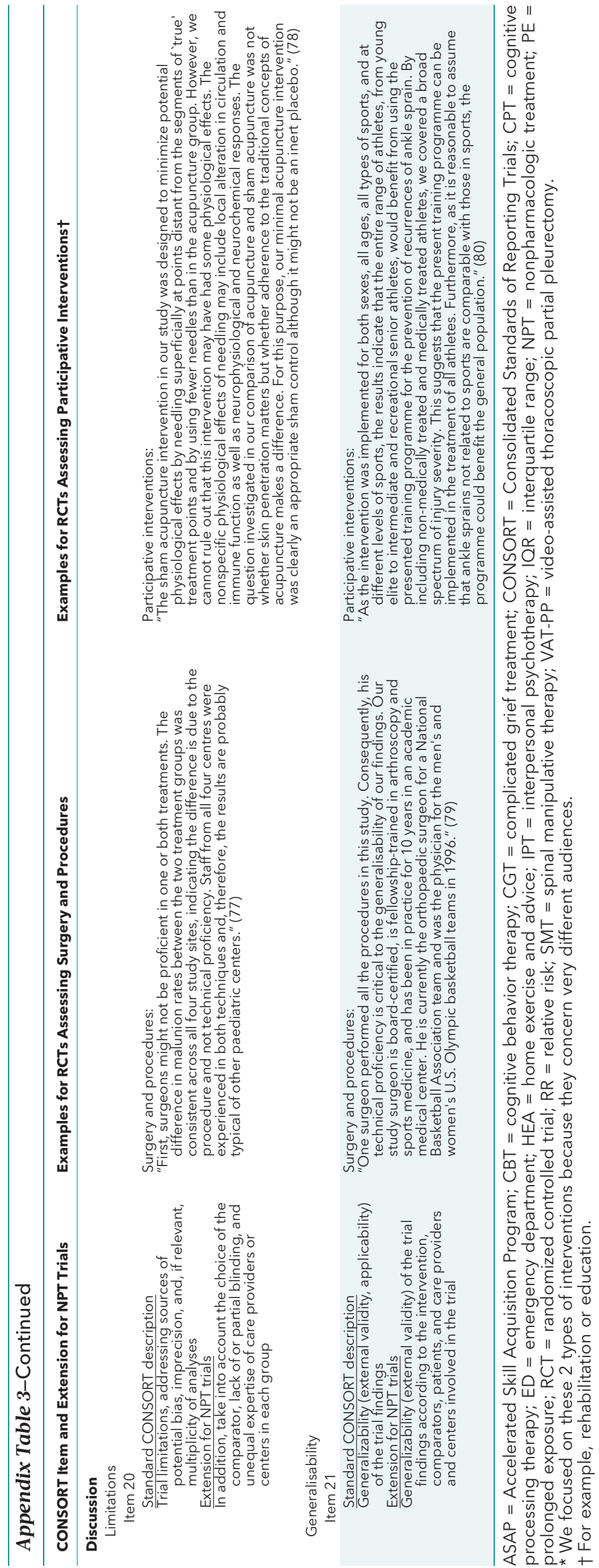


Appendix Figure 1. Example of a participant flow diagram for a single-center trial of surgery.

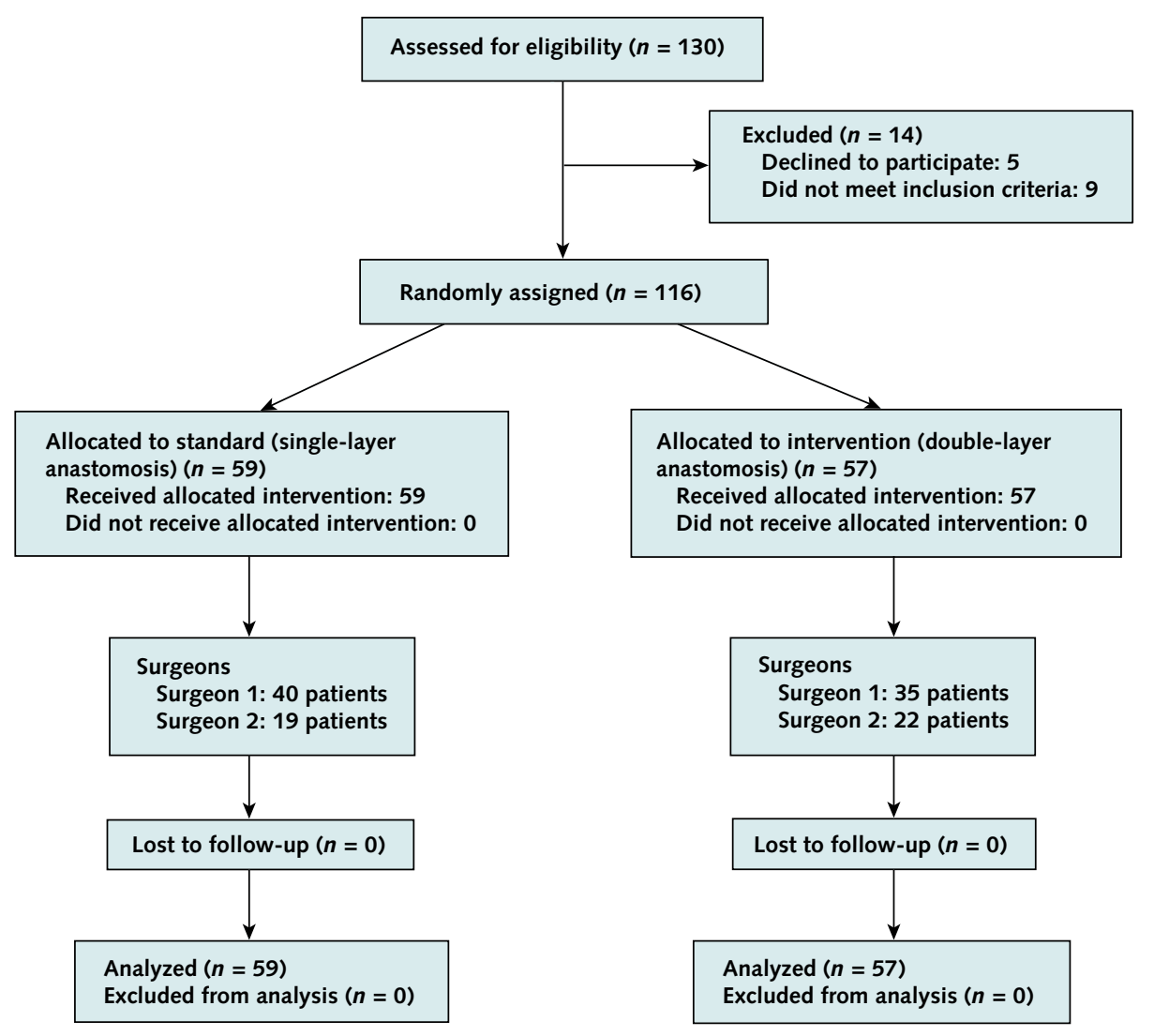

Adapted from reference 87 . 
Appendix Figure 2. Example of a participant flow diagram for a multicenter trial of participative interventions.

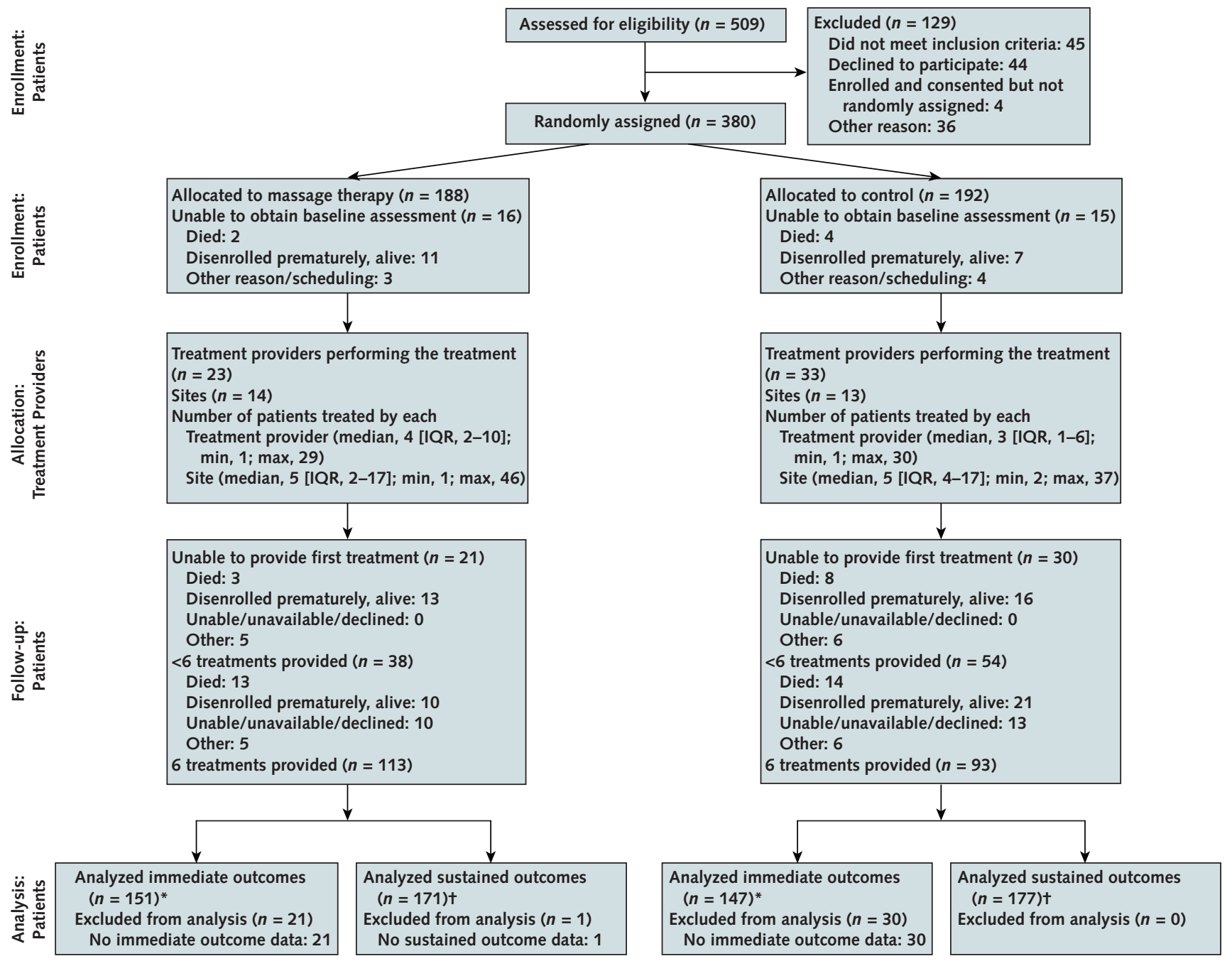

Assessments refer to the weekly or sustained outcomes. Immediate outcome data collection occurred in conjunction with every treatment session.

$\mathrm{IQR}=$ interquartile range; $\max =$ maximum; $\min =$ minimum. Reproduced from reference 81 , with permission

* Number who had any treatment: $113+38$ for massage therapy and $93+54$ for control.

† Number with baseline or any sustained outcome assessments: 188 - 17 for massage therapy and $192-15$ for control. 


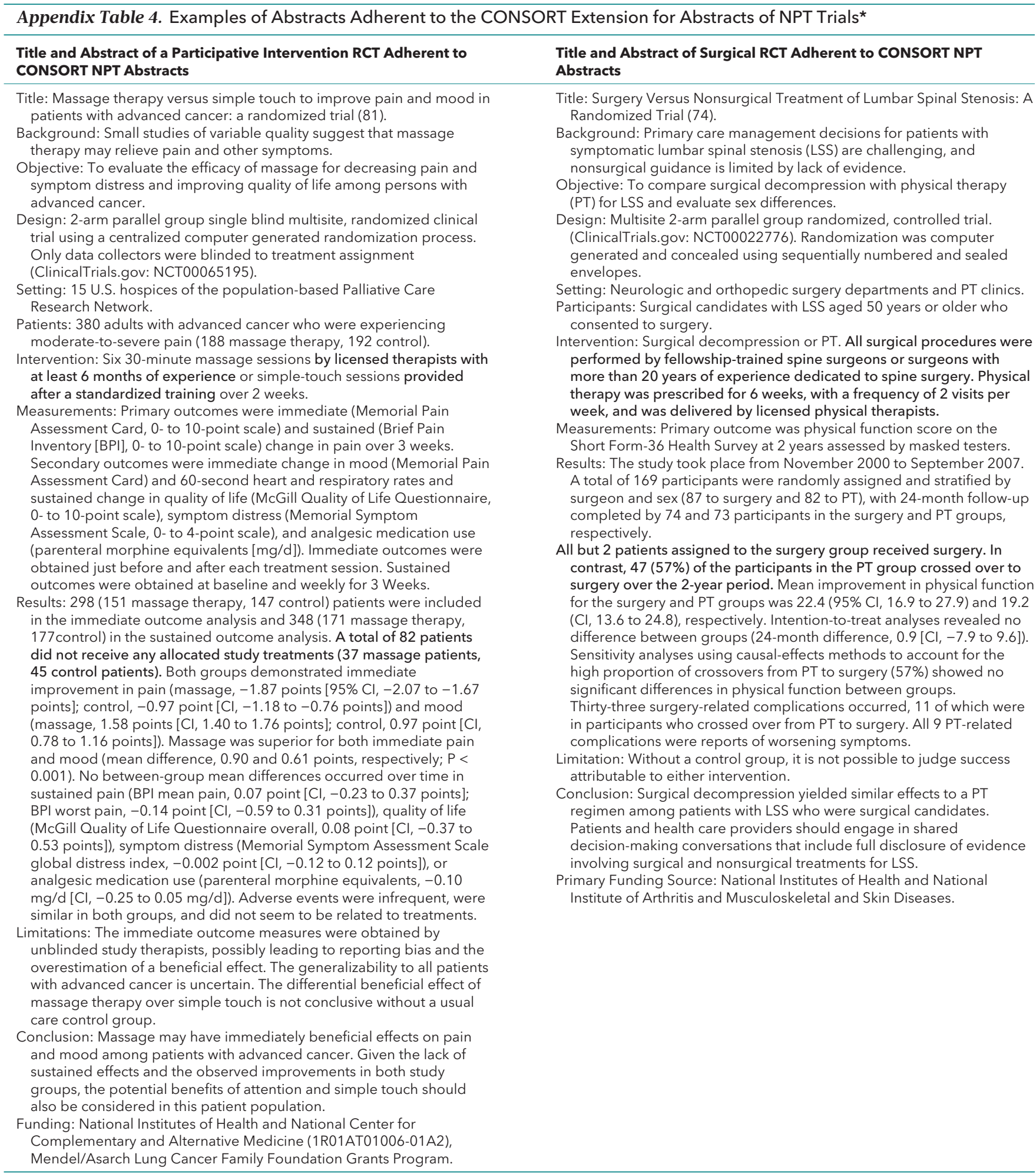

CONSORT = Consolidated Standards of Reporting Trials; NPT = nonpharmacologic treatment; RCT = randomized controlled trial.

* Original abstracts were modified to adhere to the CONSORT extension for abstracts and the CONSORT extension for abstracts of NPT trials (CONSORT NPT abstracts). Information requested for CONSORT NPT abstracts is in boldface. 
Appendix Table 5. Allocation of Care Providers to Each Trial Group

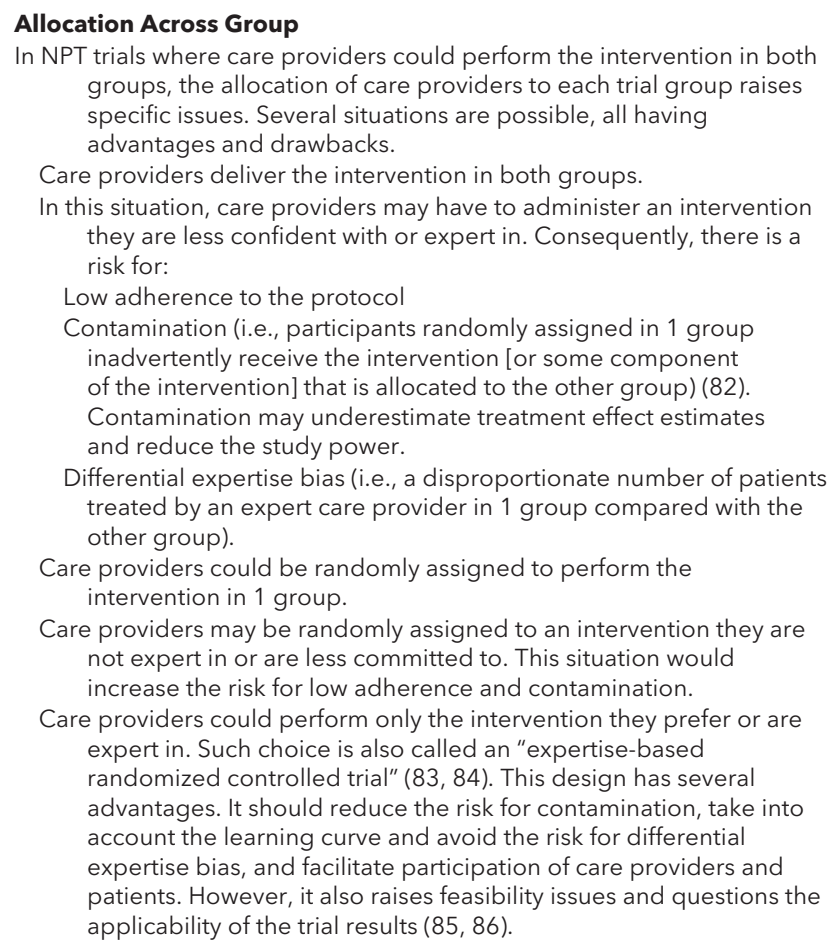

\section{Allocation Within Group}

In some NPT trials, the care providers can perform the intervention in only 1 group (e.g., surgery vs. drug or surgery vs. physiotherapy). The allocation of care providers within groups is frequently determined by logistical considerations. However, in some situations, care providers could be randomly assigned among a pool of eligible care providers.

NPT = nonpharmacologic treatment. 